International Review of Research in Open and Distributed Learning Volume 22, Number 1

February - 2021

\title{
Using Open Educational Resources at Viterbo University: Faculty and Student Feedback
}

Alissa L. Oelfke, PhD, Jennifer A. Sadowski, PhD, Cari Mathwig Ramseier, MA, Christopher Iremonger, PhD, Katrina Volkert, MBA, Emily Dykman, DMin, Lynne Kuhl, MSN, and Annie Baumann, MLIS

Viterbo University

\begin{abstract}
This study evaluated a coordinated and collaborative pilot implementation of open educational resources (OER) across multiple disciplines including nursing, accounting, environmental science, religious studies, and finance. Participating faculty were qualitatively surveyed regarding their experience creating and implementing OER in a course. Students were surveyed on their perceptions of OER quality, cost savings, and ease of use. Faculty had an overall positive experience with OER, believing there was a significant benefit to students in cost savings while maintaining learning quality. Faculty felt the OER implementation process took a significant investment of time and recommended that faculty should be compensated for creating and implementing OER materials in future courses. Students overall showed positive responses to using OER in their course; the majority of students agreed with the OER cost savings, quality of OER resources, ease of using OER, and they trusted the use of OER materials. Older students (over 30 years) were more likely to state they would print out OER materials rather than read them online (as compared with students 30 and under). Senior-level students agreed significantly more than did freshman-level students that OER presented a cost savings. Faculty recommendations from this study included focusing on courses with very high textbook costs and courses that would impact the greatest number of students. Additionally, faculty recommended a follow-up revision process to keep OER materials current after implementation.
\end{abstract}

Keywords: open educational resources, OER, open textbooks, textbook cost savings, free textbooks 


\section{Introduction}

According to Kristof (2018), the average cost of college textbooks has risen in the last 10 years at a pace four times faster than the rate of inflation, and the national average cost of textbooks per student is over $\$ 1,200$ per academic year. In addition, $65 \%$ of students admitted they had skipped purchasing a required textbook at some point because they could not afford it (Kristof).

The use of open educational resources (OER) is one potential solution to the high and rising cost of college textbooks. Open educational resources are educational materials (typically electronic) available for little or no cost including textbooks, course readings, and other learning content such as simulations, games, syllabi, quizzes, and assessment tools. These materials are generally released under a Creative Commons or similar license that supports open or nearly open use of the content (Atkins et al., 2007). The William and Flora Hewlett Foundation (2021) provides the following similar definition of OER:

At Hewlett, we use the term "open education" to encompass the myriad of learning resources, teaching practices and education policies that use the flexibility of OER to provide learners with high quality educational experiences. Creative Commons defines OER as teaching, learning, and research materials that are either (a) in the public domain or (b) licensed in a manner that provides everyone with free and perpetual permission to engage in the $5 \mathrm{R}$ activities- retaining, remixing, revising, reusing and redistributing the resources. (para. 4)

It is important to recognize that the licensing varies depending on the resource. Not all resources can be adapted or modified, and not all can be redistributed with or without modifications. Some OER require that if the content is utilized or redistributed, any images or text must contain sourcing acknowledgements, which may include live links to the original sources. Perhaps one of the most complex aspects of using OER to teach a course is having a good understanding of what is allowable-from a licensing standpoint-for the particular content an instructor might choose to use.

Textbooks have traditionally been the means for delivering content to students in higher education, and most faculty believe their students learn better when they have read their assigned textbook readings before coming to class (Hilton, 2016). However, due to the high price of textbooks, and faculty who are conscious of how much their students spend on them (as well as a general awareness that if textbooks are unaffordable, students will do without them), some instructors are substituting OER for books (Hilton, 2019).

There are many good arguments for using OER in place of expensive textbooks. According to Schaffhauser (2014), the following benefits can be experienced by students and faculty when courses utilize OER:

- All course materials are immediately accessible to students, so there is no reason to do without the materials as students sometimes do when they cannot afford the textbook.

- The savings experienced by students can be significant. 
- Students are more likely to enroll in courses that use OER over courses that use a textbook.

- Faculty do not need to make multiple changes to the content as they do when a textbook has a new edition available.

OER may also be beneficial to international students. Delgado et al. (2019, p. 200) found that international students were positively impacted by the use of OER, potentially because some of the content included subtitled videos, allowing them to view the material repeatedly.

Many faculty have reservations and face obstacles in adopting OER instead of a textbook. One study found that although more professors know about free textbook options and agree that the cost to students is important to them, only a very small percentage have adopted them for use in their classes (Blumenstyk, 2016b). The barriers perceived by faculty include finding enough resources in the subject they teach, lacking a catalog of potential resources they could use (Blumenstyk, 2016b), and lacking the time to collect the materials, vet them, and design the course around them (Blumenstyk, 2016a).

The literature around OER has focused on two main questions (Hilton, 2016). The first question relates to whether students can achieve the learning outcomes at the same level using OER rather than textbooks. The second question is whether the students and instructors perceive the OER to be of high quality. Hilton's (2016) study found that students generally achieve the same learning outcomes using OER as they would have achieved with the textbook, while also experiencing significant cost savings. Hilton also found that both student and faculty perceptions of OER were generally positive. They believed that OER are of comparable quality to more traditional textbooks.

At Viterbo University, although many faculty are aware of the cost savings for students when using OER, there has not been a large shift away from textbooks. Faculty resistance to adopting OER rather than traditional textbooks may center on a few important factors, including the time it takes to find the resources and design the course around them.

For many faculty, a shift to using OER instead of textbooks without significant support from their university has not been feasible. In order to explore what it takes to convert course content to OER, a group of faculty members at Viterbo University began a pilot program where six faculty members, an electronic resource librarian, and an instructional designer worked to move course content from textbooks to OER content in five courses. The university administration provided support for this project through an institutional grant and maintained a strong interest in the findings. With the growing number of student evaluation comments regarding the cost of education and high costs of purchasing required textbooks, university administration considered causes and impact of financial hardship on student progression and retention.

The faculty group working on this project began meeting in April, 2017. They continued to meet on a regular basis throughout the 2017-2018 academic year to compare notes as they gathered and vetted OER materials, designed their courses, and taught their courses. In this case study, the faculty-led pilot group at Viterbo University compiled common themes from their curricular design process notes. In addition, the 
pilot group gathered feedback from the students enrolled in five courses regarding their perceptions of the value and quality of the materials as well as their perceptions of their own learning using OER.

Early in the process, the pilot group members questioned what could be done to support the faculty as they converted their courses to utilize OER content. According to the pilot study group and recent literature, deans, presidents, and academic administrators can focus on supporting those faculty who decide to use OER. This support could come in several different forms, including the following:

- instructional design team members who can help the faculty create course content using OER;

- library staff who can help faculty curate OER content;

- philanthropic attention to support projects that build an open collection in a given discipline (Blumenstyk, 2016a);

- public recognition of the faculty who are leading the way in creating courses using OER (Blumenstyk, 2016a); and

- giving faculty who have converted a course to OER the opportunity to share their work with faculty who do not have experience with OER.

Many of these supports were put in place in this pilot program at Viterbo University, including (a) institutional funding for participating faculty, (b) support of an instructional designer and an electronic resources librarian, (c) an opportunity for participants to share their work with other faculty, and (d) public recognition of the members of the pilot group. The objectives of the study included:

- Evaluating the student experience of using newly designed OER materials across five disciplines through their perceptions of cost, quality, and ease of use.

- Evaluating the faculty perceptions related to their experience of finding, creating, and implementing OER materials across five disciplines.

\section{Research Method}

Several research questions were under investigation in this study, based on the two groups that were included. The first group included the faculty who were participating in the pilot project. The pilot faculty group was gathered, and meeting notes were documented and organized around frequently-noted topics. By learning about and documenting their experiences in gathering and vetting the OER materials and designing their courses around those materials, the investigators were better able to understand how to help faculty navigate this process more effectively and efficiently in the future. 
The second group under investigation in this study was the group of students enrolled in the courses using OER. The intent was to investigate student perceptions of OER materials related to cost savings, ease to access, preference of printed versus electronic versions, level of trust and quality of information, and impact on their learning (see Figure 1 for details).

The questions were formatted as five-point Likert items in a student survey using Qualtrics; students were asked to identify their level of agreement (or disagreement) with each statement. Students were asked to respond to nine statements, where $1=$ strongly disagree, $2=$ disagree, $3=$ neither agree nor disagree, $4=$ agree, and $5=$ strongly agree .

Student participants were recruited by sending an explanatory electronic letter out to all students who were enrolled in a course that was part of the OER project. The letter was sent via e-mail from each instructor to their entire roster for the course and included a link to a Qualtrics survey. Upon opening the survey link, respondents received instructions for completing the survey, an assurance that the respondents would not be identifiable to the researchers, an option to opt out of the survey, and a statement regarding the protection of the confidentiality of their responses (Note: Viterbo's Institutional Review Board (IRB) granted an exclusion from IRB review, as this project was characterized as quality improvement.). The respondents were asked to reply to the survey within one week. A second reminder e-mail was sent four days after the first message, and it included the cover letter information and the survey link again, along with a reminder to reply by the established deadline. The survey settings only allowed one response per IP address, to prevent multiple responses from the same individual.

In the survey, students were asked to identify themselves in the following demographic groups: (a) age; (b) gender; (c) student type (returning adult student or traditional undergraduate student); (d) year (freshman, sophomore, junior, or senior); and (e) their status as a full-time or part-time student. From the list of five courses in the pilot project, students were also asked to identify which course they were taking in OER format, and whether the format was online or in the classroom. Using each of these grouping variables to make comparisons in responses, several statistically significant differences were identified in the survey data.

Statistical analyses were conducted with SPSS statistical analysis software (version 24). Due to the nonparametric nature of the five-point Likert items, a series of Mann-Whitney U and Kruskal-Wallis tests were run using SPSS statistics analysis software (version 27; Ranganathan et al., 2016). As three of the grouping variables, including age, returning adult student versus traditional student status, and full-time versus parttime status were likely to have overlap or may be subsets of each other, Bonferroni-corrected $p$-values for tests with these groups were reported in the analysis. 


\section{Analysis of Research}

\section{Faculty Experience}

Participating faculty discussed the challenge of finding and vetting course content. Some faculty reported difficulty with finding OER content in their discipline, particularly up-to-date content. Others reported finding so much content that it was difficult to narrow down what they wanted to use. For some, the challenge was in finding a single source, so they selected content from multiple sources and had to do the work of weaving it together in a way that created a logical sequencing of content and a positive, meaningful learning experience for the students.

Faculty also experienced a steep learning curve in their first attempts to select OER content and use it to create a pedagogically sound course. Although they received assistance with curating content from the electronic resource librarian, and assistance with course design from the instructional designer, there was a wide range of preparation time to prepare for a three-credit course. Preparation ranged from 50 to 120 hours of faculty time, plus 10 to 25 hours of the electronic resource librarian's time, and additional time from the instructional designer. In all cases, faculty indicated this was in excess of the time they would normally spend on preparation for the particular courses within which the OER content was being added, similar to findings by other universities using OER (McGreal, 2019). Had textbooks been used, the electronic resource librarian's time would have been zero hours for any of these given courses. Instructional design time was also in excess of normal time spent assisting faculty with content flow, activity development, and formatting.

At times, the OER content did not transition well from one topic to the next, especially when faculty were working with multiple resources to cover all the desired content for the course. When multiple resources were utilized, there was a related increase in the amount of time it took to prepare the materials for the course. Similar to the experiences at other universities (Dennen \& Bagdy, 2019; Dudek et al., 2019; McGreal, 2019), faculty spent time authoring transitional content, developing practice problem sets and case studies, and writing quiz or exam questions and answer keys, as these are typically included in the instructor resources from many commercial textbook publishers. They also spent time preparing tutorial videos that would demonstrate problem or case study solutions.

In some instances, faculty were able to select a single electronic textbook, and the university purchased a multiple-user license to share the text with all students in the course. This practice steeply reduced the amount of time faculty spent on designing the course, but also resulted in a few challenges. Students in the courses sometimes had technical issues that would not occur with a paper textbook, including that the electronic text would freeze while they were using it. Faculty reported that some students had difficulty navigating the electronic text, and difficulty printing out materials if they desired to do so, while these would not be issues if they were utilizing a hard copy textbook.

In the months following the initial offering of the five courses in the pilot project, faculty acknowledged that the courses needed some additional development. Improvements to the content were needed each time the 
courses were offered. This consumed additional preparation time for faculty, as well as some additional time with the electronic resource librarian and the instructional designer, but it was necessary to address any issues with the content that arose as it was being utilized in the course.

Despite several difficulties, faculty who participated in the pilot study were pleased with the result, and excited to be able to teach from the OER content on a regular basis. Faculty who had taught their courses multiple times reported that subsequent offerings improved the quality of the course, but also allowed the instructor to focus on the students and meeting their learning needs, with less time spent on preparation of course materials. Perhaps there will be some time savings in subsequent semesters due to the faculty being very familiar with the content, having written some of the practice sets and case studies, and having recorded video tutorials.

Overall, faculty who participated in the pilot project at Viterbo University believed there was great potential for OER if resources can be made available to assist faculty with the workload to create a good course and a good learning experience for students.

\section{Cost Savings for Students}

One of the intended outcomes of the pilot project at Viterbo University was to reduce the cost of course materials for the students. To that end, the textbook costs that would be eliminated by switching to OER content were identified for each course. This savings amount was applied to the average number of students per section, and then multiplied by the number of sections typically running in one year. Table 1 demonstrates the total savings per year for each course, as well as the total annual savings for all five of the piloted courses. Total savings per student per course was approximately $\$ 160$.

\section{Table 1}

Cost Savings by Course

\begin{tabular}{|c|c|c|c|c|c|}
\hline Course & $\begin{array}{l}\text { Textbook cost } \\
\text { savings per } \\
\text { student }\end{array}$ & $\begin{array}{l}\text { Students per } \\
\text { section }\end{array}$ & $\begin{array}{c}\text { Sections per } \\
\text { year }\end{array}$ & $\begin{array}{l}\text { Students } \\
\text { per year }\end{array}$ & $\begin{array}{l}\text { Savings per } \\
\text { year }\end{array}$ \\
\hline $\begin{array}{l}\text { OMGT } 318 \\
\text { (online) }\end{array}$ & $\$ 240.00$ & 15 & 3 & 45 & $\$ 10,800.00$ \\
\hline $\begin{array}{l}\text { OMGT } 308 \\
\text { (online) }\end{array}$ & $\$ 266.00$ & 15 & 3 & 45 & $\$ 11,970.00$ \\
\hline ENVS 101 (online) & $\$ 115.00$ & 22 & 3 & 66 & $\$ 7,590.00$ \\
\hline ENVS $101(\mathrm{~F} 2 \mathrm{~F})$ & $\$ 146.00$ & 20 & 2 & 40 & $\$ 5,840.00$ \\
\hline $\begin{array}{l}\text { RLST } 305 \text { (online, } \\
\text { blended, F2F) }\end{array}$ & $\$ 94.00$ & 22 & 5 & 110 & $\$ 10,340.00$ \\
\hline NURS 290 (F2F) & $\$ 173.00$ & 200 & 1 & 200 & $\$ 34,600.00$ \\
\hline & $\$ 1,034.00$ & 294 & 17 & 506 & $\$ 81,140.00$ \\
\hline
\end{tabular}




\section{Student Survey Results}

Figure 1 provides the students' responses to nine statements. It is clear from the results that the majority of respondents felt the OER materials did provide a cost savings (85.71\% responded agree or strongly agree), and the materials were easy to access (80.96\% responded agree or strongly agree). Also, $92.07 \%$ of the respondents said they trusted the sources of information used in the content of the course, by indicating they agreed or strongly agreed with that statement. And $84.13 \%$ of the respondents agreed or strongly agreed that the resources provided were of high quality. Lower levels of agreement, yet still representing a strong majority, indicated respondents felt they were able to learn successfully using the non-textbook materials (73.01\% agree or strongly agree), using OER was not detrimental to their learning (72.58\% agree or strongly agree), and if they had the opportunity, they would take a class using OER again (74.6\% agree or strongly agree).

\section{Figure 1}

\section{Student Perception Survey Results}

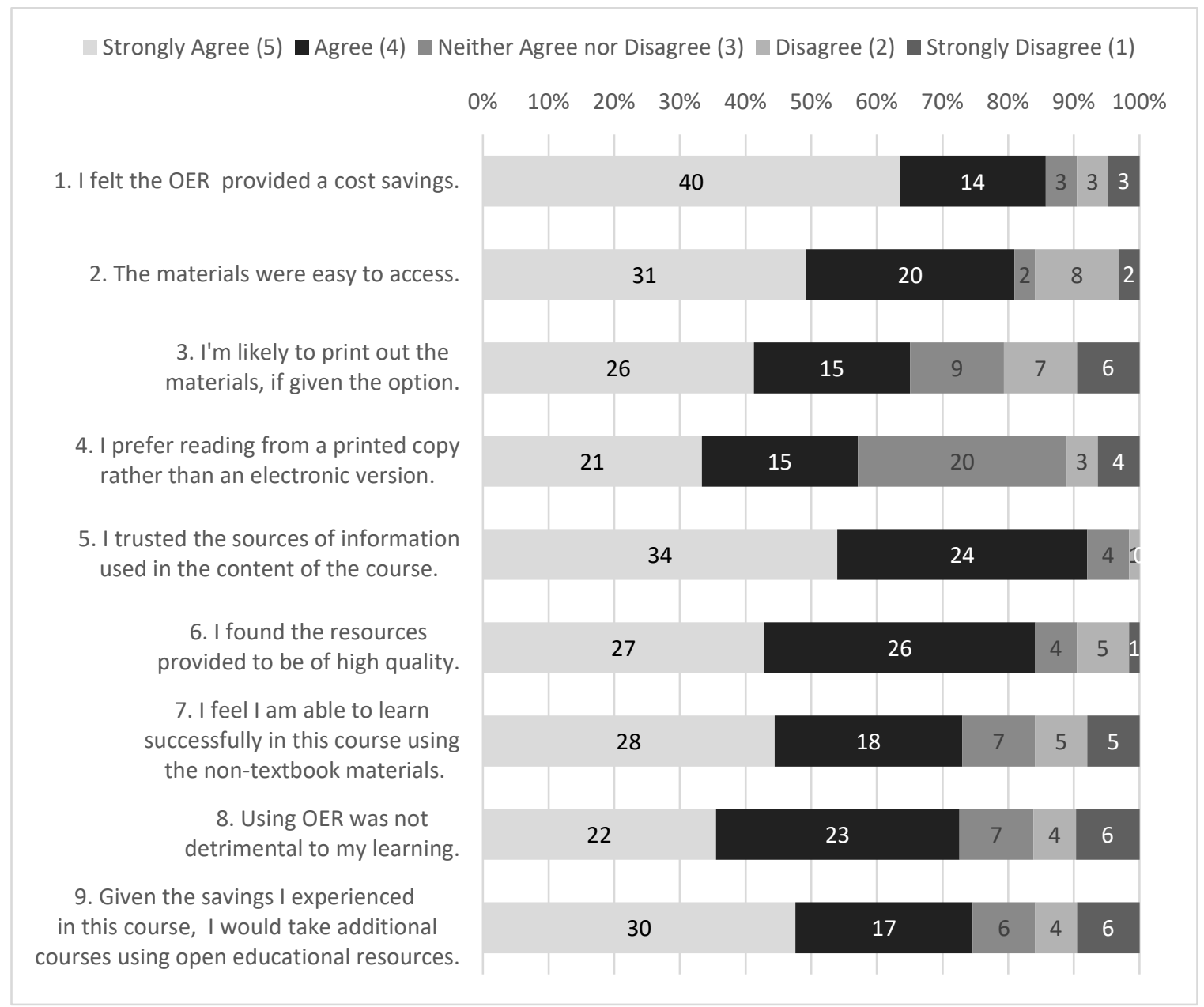


Statements 3 and 4 represented the greatest level of variation in responses. Among the respondents, $65.08 \%$ indicated they agreed or strongly agreed that they were likely to print out the materials if given the option; $57.14 \%$ agreed or strongly agreed that they preferred reading from a printed copy rather than an electronic version.

In statement 3 , the 30 years and under age group $(n=32)$ was significantly less likely to print out the materials if given the option compared with the over 30 age group $(n=30$; Mann-Whitney $U: Z=-3.331$, Bonferroni corrected $\rho=0.003)$. Other similar demographics had the same result. Returning adult students ( $n=33$ ) more strongly agreed they would be likely to print out the materials than did traditional students ( $n=30$; Mann-Whitney $U: Z=-2.710$, Bonferroni corrected $\rho=0.021)$, and part-time students $(n=22)$ more strongly agreed they would be likely to print out the materials than did full-time students ( $n=41$; Mann-Whitney $U: Z=-3.436$, Bonferroni corrected $\rho=0.003$ ). General qualitative feedback from students across courses showed that some students preferred studying from a textbook for tests and quizzes. Returning adult students are generally older, and more likely to be part-time students, so providing an option to print out OER materials is important. In statement 5 , females more strongly agreed that they trusted the sources of information used in the content of the course than did males (Mann-Whitney $U: Z=$ -2.400, $\rho=0.016$ ). This could be a difference in opinion based on gender, or it could be related to the fact that the majority of students who took the survey were female (48 females vs. 15 males).

When respondents were categorized by year, the seniors $(n=18)$ more strongly agreed that the OER materials presented a cost savings, when compared with freshmen $(n=4)$, sophomores $(n=26)$, and juniors ( $n=14$; Kruskal-Wallis: $\chi^{2}=8.295, \rho=0.040, d f=3$ ).

The data for each course suggest students in all courses agreed on most issues. However, in some cases, students significantly disagreed regarding their perceptions on the ease of access to course materials. Students in OMGT 318 (Managerial Finance) strongly agreed with the statement that the materials were easy to access, while students in RLST 305 (Theology) disagreed with this statement (Kruskal-Wallis: $\chi 2=$ 11.057, $\rho=0.026, d f=4$ ). These two courses were delivered in different ways. The content of OMGT 318 was placed in learning modules that students accessed via the LMS. In addition, the content was also placed into PDF files that could be printed if students chose to do so. In RLST 305, students accessed course materials via an online electronic textbook purchased with a university-wide license. In order to access the online text, students were routed to the library Website via a Web browser. Some students indicated that the text in the Web browser froze as they were using it, resulting in their being unable to navigate through the course material. The distinction between the way the content was delivered in these two courses likely accounts for the significant differences in students' perceptions regarding ease of access.

\section{Faculty Participant Recommendations}

Participating faculty experienced a learning curve when selecting content and developing the course site on the LMS, where the OER content was accessible. Students experienced a learning curve as well. It took them some time to understand the options available to them (such as printing the materials or accessing the multi-user e-book). Once students understood a process for accessing the content, they appreciated the cost 
savings; a majority felt it was worth the experience, and they would take another course using OER content, if given the opportunity.

When reflecting upon their experience creating courses using OER content, participating faculty recognized that not all classes are appropriate for OER content. They found that sometimes the quality of illustrations and the value of the simulation-type exercises provided by book publishers is not currently available in OER content. Other courses might lack available OER content because what is available as OER is not current, or it does not reflect the best evidence/research as required by practice standards (e.g., tax code changes in an accounting course, national accreditation standards for a nursing class).

Faculty involved in the pilot study suggested that if a university decides to take on a similar initiative to convert courses to using OER content rather than textbooks, a proposal process should be implemented. This way interested faculty can investigate, with the help of an electronic resource librarian, what materials are available and understand how they can be used according to the licensing requirements, as well as the amount of work that will be involved in implementing OER for the specific course.

In addition to a proposal process, faculty in the pilot study recommended a compensation plan for faculty who develop courses utilizing OER content. This is necessary because of the potentially extensive amount of time involved in reviewing content, authoring transitional content, creating practice problem sets or case studies, and recording videos. The compensation could be paid with the understanding that the university owns the content and course design going forward, so it could potentially be utilized by other instructors in the future, including adjunct faculty.

It is important for the development of OER content to focus on where there can be the most impact on students-through both cost savings and improved learning. Faculty noted that not all courses are good candidates for using OER content instead of a commercial textbook. Careful consideration should be given to the types of courses that make good candidates for this type of transition. This may include the following:

- Introductory courses with a single source or well-developed OER content available for use, with more robust support materials to reduce the need for faculty to author transitional content, practice sets, case studies, and videos.

- Courses offered in a format that is highly interactive, with content and course design supporting strong interaction between faculty and students, including using various media to satisfy the varied learning preferences of students.

- Courses where textbooks are costly, and where OER content is easily accessible.

In addition to the types of classes that would lend themselves to the use of OER, some important considerations must be given to whether the materials used can be printed easily. Some OER are difficult to print by nature of how they are published, such as Web pages versus PDF documents that are available for download. 
Finally, faculty who participated in the pilot project recommended that a follow-up process be built into the requirements of the proposal to convert courses to OER. This should include a policy for reviewing and updating the content on a regular basis. OER should also be made available to students and instructors in future sections of the course, so that the institution will benefit over the long term from the investment in course development work.

\section{Conclusions}

Several conclusions can be drawn from the student perception survey data. First, when implementing OER materials, the student population that is likely to take a particular course needs to be considered. Older, returning, and part-time students prefer to have a printed copy of their materials, so careful consideration of the format that will be perceived to be the most comfortable and accessible for the predicted student population is necessary. In addition, consideration should be given to how the materials are presented within the learning management system or using links to electronic resources, to make sure access is readily available and functioning well. Students will be most satisfied if they are able to easily access and navigate the course materials.

This project was a collaborative effort to design courses around open educational resource content. It was an opportunity for faculty and administration to understand the time commitment of this kind of development work, and the challenges related to gathering and connecting information from a number of different sources. Faculty discovered that partnering with an electronic resource librarian and an instructional designer were critical steps in successfully gathering content and making it available to students in a structured way. Faculty participants also had a positive experience with OER, resulting in the belief that although the course design work required a large time commitment, students significantly benefitted via cost savings, while also maintaining the quality of the learning experience. Student responses echoed this observation, with the majority agreeing that they experienced significant cost savings, while the quality of these materials met their expectations. 


\section{References}

Atkins, D. E., Brown, J. S., \& Hammond, A. L. (2007, February). A review of the open educational resources (OER) movement: Achievements, challenges, and new opportunities [Report to the William and Flora Hewlett Foundation]. https://pdfs.semanticscholar.org/8d16/858268c5c15496aac6c88ofgf50afd964ob2.pdf

Blumenstyk, G. (2016a, July 12). As free textbooks go mainstream, advocate says colleges should do more to support them. The Chronicle of Higher Education. https://www.chronicle.com/article/AsFree-Textbooks-Go/237082

Blumenstyk, G. (2016b, July 26). More professors know about free textbook options, but adoption remains low. The Chronicle of Higher Education. https://www.chronicle.com/article/MoreProfessors-Know-About/237252

Delgado, H., Delgado, M., \& Hilton, H. (2019). On the efficacy of open educational resources: Parametric and nonparametric analyses of a university calculus class. International Review of Research in Open and Distributed Learning, 2O(1). https://doi.org/10.19173/irrodl.v20i1.3892

Dennen, V.P., \& Bagdy, L.M. (2019). From proprietary textbook to custom OER solution: Using learner feedback to guide design and development. Online Learning, 23(3), 4-20.

https://doi:10.24059/olj.v23i3.2068

Dudek, B., Duran, D., \& Parscal, T. (2019). Wide open voices: Experiences of OER course developers. Online Journal of Distance Learning Administration, 22(2). https://www.westga.edu/ distance/ojdla/summer222/dudek_duran_parscal222.html

Hilton, J. (2016). Open educational resources and college textbook choices: A review of research on efficacy and perceptions. Education Technology Research and Development, 64(4), 573-590. https://doi.org/10.1007/s11423-016-9434-9

Hilton, J. (2019). Open educational resources, student efficacy, and user perceptions: A synthesis of research published between 2015 and 2018. Education Technology Research and Development, 68, 853-876. https://doi.org/10.1007/s11423-019-09700-4

Kristof, K. (2018, January 26). What's behind the soaring cost of college textbooks? MoneyWatch. https://www.cbsnews.com/news/whats-behind-the-soaring-cost-of-college-textbooks/

McGreal, R. (2019). A survey of OER implementations in 13 higher education institutions. The International Review of Research in Open and Distributed Learning, 2O(5), 141-145. https://doi.org/10.19173/irrodl.v20i5.4577 
Ranganathan, P., Pramesh, C. S., \& Buyse, M. (2016). Common pitfalls in statistical analysis: The perils of multiple testing. Perspectives in Clinical Research, 7(2), 106-107. https://doi.org/10.4103/22293485.179436

Schaffhauser, D. (2014, August 27). Complete guide to open educational resources. Campus Technology. https://campustechnology.com/articles/2014/08/27/complete-guide-to-open-educationalresources.aspx

William and Flora Hewlett Foundation. (2021). Open education. https://hewlett.org/strategy/openeducation/

\section{Athabasca University}

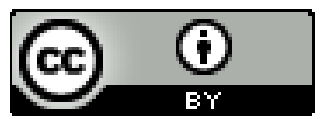

